\title{
Effect of Cement Injection on Shear Behaviour of Jointed Rock based on Mohr-Coulomb Criterion
}

\author{
Rizto Salia Zakri, Ganda Marihot Simangunsong, Nuhindro Priagung Widodo \\ Departement of Mining Engineering, Institut Teknologi Bandung, Bandung 40191, Indonesia
}

\begin{abstract}
Common problem in mining activity is instability caused by jointed rock mass. The strength of jointed rock mass can be increased by cement injection. An artificial rock sample made from dental plaster type of moldano tara is used in this study to evaluate the influence of cement injection to the strength of jointed rock sample. The roughness of joint surface are obtained from the natural rock joints and divided into three groups of Joint Roughness Coefficient (JRC) values based on Barton criteria. The injection materials are mixture of cement and water with the ratio of water and cement of 4: 5 and 3: 2. This artificial samples are then subjected to direct shear tests. The test results are analyzed by Mohr-Coulomb criterion to obtain the cohesion and internal friction angle. It is revealed that cohesion and internal friction angle increased for injected rock sample. The strength increase varies by JRC condition. For Sample with JRC value between 8-10, the study find that injection material with water to cement ratio of 4:5 is more effective than cement injection with ratio of 3:2. For JRC value between 12-14, 16-18, and 18-20, it is found that cement injection with ratio of 3:2 is more effective than 4:5.
\end{abstract}

\section{INTRODUCTION}

Common problem in mining activity is instability of slope or tunnel. In natural conditions, rock mass will be affected by structure and fracture, where this conditions will give effect to the strength of rockmass. One of the way to increase the strength of rock mass is to use cement injections on the jointed rocks, so called grouting. Due to the increasing use of grouting as an important in stabilization and reinforcement of rock mass, investigation of the behaviour of grouted joints to evaluate their effect on rock mass behaviour becomes important. Grouting is a method where a grout material injected into the fractures, pores, or fissures of a rock or soil body and enchances its properties (Nonveiller,1989). Joint is a term used in rock mechanics include of all weak structures except faults (Arif,1989). The result of grouting are incresing rock mass strength and decrease number of deformation (Nonveiller, 1989).

Because of many samples are needed in this study for each roughness condition, and considering the fact that in natural condition it is difficult to obtain sample with same roughness. In this study the samples were made from an artificial material using dental plaster. Salamian (2017) have shown that dental plaster is the best material for artificial joint, because it has a high strength and the less curing time.

Grouting material was made by mixing the portland compossite cement and water with certain ratio. Grouting material with high cement-water ratio will obviously has high compressive strength (Indrarata, 2000). However, it should be noted that grout with low water cement-ratio is the best composition for jointed rock with low apperture (Nonveiller, 1989). Houlsby (1982) gives some recommendation for grouting composition based on joint apperture as shown in Table 1.

For low aperture joint, Salamian (2017) found that grouting with water to cement ratio of 2:1 will increase the cohesion of rock than water to cement ratio of $1: 1$. Joint roughness which is usually defined by JRC value will give proportional effect on a shear strength.
Consequently in this study the effect of joint roughness is also evaluated.

Table 1. Recomendation of grotuing composition

\begin{tabular}{cc}
\hline Average Joint Aperture & Water-Cement Ratio \\
\hline$<1$ & $3: 1$ \\
$=1$ & $2: 1$ \\
$>1$ & $1: 1$ \\
\hline
\end{tabular}

To summarize this study, the natural joint was reproduced by a silicon rubber, after that the dental plaster was used as the artificial sample, and then grouted. The test samples were made in four types of JRC values and grouted with two condition of grouting materials. All sample were subjected to the direct shear test.

\section{RESEARCH PROCEDURE}

The objective of this study is to investigate the grouting effect on the shear strength of joint with various roughness.

\subsection{Fabrication of artificial joints}

Samples were made using materials include of cement and sand and fabricated to a cylinder shape. After several days, the specimen was manually fractured in the middle to get the artificial joint. The JRC value was measured and printed to the artificial sample. The same procedure was performed using different composition of cement and sand to finally obtain four types of JRC condition. A silicon rubber was molded above the artificial joint to be used as a casting material. Following the casting process, the rocks joints were fabricated using the dental plaster. The uniaxial compressive strength of dental plaster is $17.93 \mathrm{MPa}$. It needs less than 15 minute for casting process, and just 7 days to reach maximum strength. The result of casting process is shown in Fig.1. 


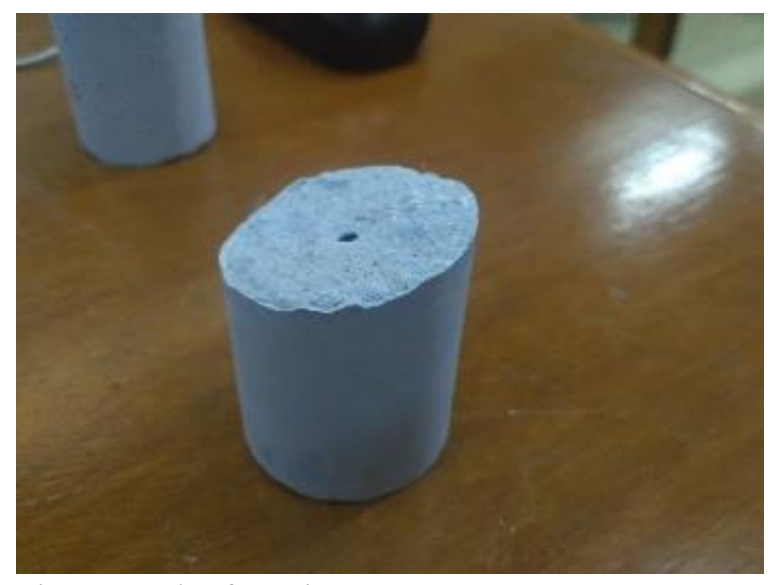

Fig. 1 Result of Casting Process

\subsection{Joint Roughness Coefficient Measurement}

Barton comb was used to profile the joint surface. The result of profiling was then drawn in a milimetre block and digitized. By using Li and Zhang (2015) equation, the JRC value was calculated as follow,

$$
\begin{gathered}
J R C=137,1739(S F)^{0,5}-3,9998 \\
S F=\frac{\sum_{i-0}^{n-1}\left(y_{i+1}-y_{i}\right)^{2}+\left(x_{i+1}-x_{i}\right)}{L}
\end{gathered}
$$

As the sample size is smaller than Barton's profile, the JRC was then corrected by the following equation,

$$
J R C_{n}=J R C_{0}\left[\frac{L_{n}}{L_{0}}\right]^{-0,02 J R C_{0}}
$$

It was found that the JRC value are 9.0, 13.4, 16.1 and 18.1, and respectively denoted as JRC 1, JRC 2, JRC3 and JRC4.

\subsection{Grouting Operation}

Two composition of water and cement as grouting materials were made in this study ( $4 \mathrm{~W}: 5 \mathrm{C} \& 3 \mathrm{~W}: 2 \mathrm{C})$. The grouting material is injected with pressure of $1 \mathrm{bar}$ into the artificial joint using an equipment as shown in fig 2. The properties of grouting materials are shown in table 2

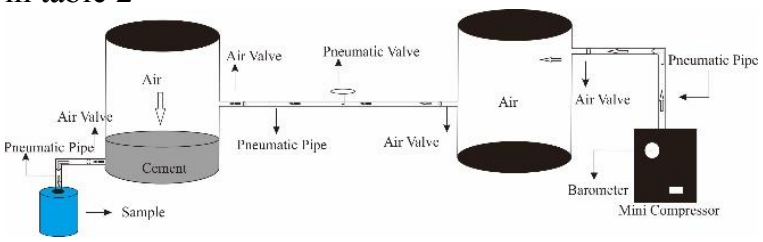

Fig. 2 Scheme of Injection Equipment

Table 2. Properties of grouting materials

\begin{tabular}{ccccc}
\hline No & $\begin{array}{c}\text { Sample } \\
\text { Code }\end{array}$ & $\begin{array}{c}\sigma c \\
(\mathrm{MPa})\end{array}$ & $\begin{array}{c}\mathrm{E} \\
(\mathrm{MPa})\end{array}$ & $v$ \\
\hline 1 & $4 \mathrm{~W}: 5 \mathrm{C}$ & 12.44 & 2534.12 & 0.30 \\
2 & $3 \mathrm{~W}: 2 \mathrm{C}$ & 5.86 & 1212.17 & 0.34 \\
\hline
\end{tabular}

This equipment consists of a mini compressor, two vacuum bottles, pneumatic pipe, pneumatic valve, and an air valve. The compressor produces pressured air into the first bottle and consequently gives pressure to the second bottle containing the grouting material. The pneumatic valve controls the air pressure in both bottles within the value of 1 bar. During the grouting process, the top and bottom of the samples were locked using a cable tie to prevent widening of joint aperture. The grouting material slowly filled the joint. After the grouting process, the samples was air dried for 28 days, to reach the maximum strength.

\subsection{Direct shear test on joints}

The type of direct shear test performed in this research was Constant Normal Load (CNL). The test was carried out in Laboratory of Geomechanics \& Mining Equipment of Institut Teknologi Bandung. Each set of sample consist of 5 specimens and given constant load of $0.2 \mathrm{kN}, 0.4 \mathrm{kN}, 0.6 \mathrm{kN}, 0.8 \mathrm{kN}$, and $0.89 \mathrm{kN}$. Adopting Mohr-Coulomb failure criteria, the friction angle $(\phi)$, cohesion (c) were obtained from the test.

\section{Test Results}

The results of direct shear tests were analyzed by Mohr-Coloumb criterion and Barton-Bandis criterion.

\subsection{Barton-Bandis criterion}

Barton-Bandis criterion considers JRC value as a component on shear strength equation, the shear strength is defined as follow,

$$
\tau=\sigma_{n} \tan \left(J R C \log 10\left(\frac{J C S}{\sigma_{n}}\right)+\phi_{r}\right)
$$

Plotting the test results into the Barton-Bandis criterion, the residual friction angle is depicted in fig 3.

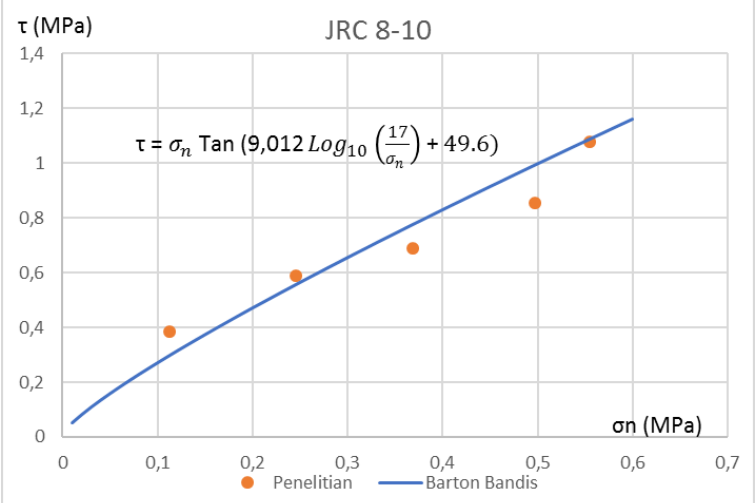

Fig. 3 Fitting Barton-Bandis Equation with test result

To validate the value of residual friction angle, the $\mathrm{R}^{2}$ value, Root Mean Square Error (RMSE) and Variance (VAF) are shown in Table 3.

Table 3. Statistical Parameters

\begin{tabular}{cccc}
\hline Sampel & RMSE & VAF & $\mathrm{R}^{2}$ \\
\hline JRC 1 & 0.09 & $88 \%$ & 0.96 \\
JRC 2 & 0.10 & $84 \%$ & 0.91 \\
JRC 3 & 0.09 & $90 \%$ & 0.93 \\
JRC 4 & 0.05 & $97 \%$ & 0.97 \\
\hline
\end{tabular}


Then, to get peak value of cohesion and friction angle, another equation developed by Prassetyo (2017) is used,

$\tan \phi_{t}=\tan \left[J R C \log _{10}\left(\frac{J C S}{\sigma_{n}}\right)+\phi_{r}\right]-\left(1+A^{2}\right) \frac{J R C}{l n_{10}}$ and the peak cohesion value can be obtained by the following relationships,

$\mathrm{C}_{\mathrm{t}}=\sigma_{\mathrm{n}} \mathrm{B}$

$\mathrm{A}=\tan \left[J R C \log _{10}\left(\frac{J C S}{\sigma_{n}}\right)+\phi_{r}\right]$

$\mathrm{B}=\left(1+A^{2}\right) \frac{J R C}{l n_{10}}$

The peak cohesion and peak internal friction angle are obtained as shown in Table 4.

Table 4 Cohesion and Internal Friction Angle Value for natural conditon

\begin{tabular}{ccc}
\hline JRC & Cohesion $(\mathrm{MPa})$ & $\begin{array}{c}\text { Internal Friction } \\
\text { Angle }\left(^{\circ}\right)\end{array}$ \\
\hline 1 & 0.100 & 62.02 \\
2 & 0.181 & 58.83 \\
3 & 0.266 & 58.00 \\
4 & 0.401 & 57.00 \\
\hline
\end{tabular}

\subsection{Shear stress-normal stress plot}

The plots corresponding to each joint were established according to maximum shear stress and residual shear stress, indexed with Peak and Residu respectively, and each set of points was fitted into a line. The slope of the fitted line denotes the friction coeffcient and Yintercept represent the cohesion of the joint, which where determined for residual shear stress and maximum shear stress in all modes of joints. It was observed that residual cohesssion does not cross from the zero point the graph, malinly due to the injected material in the joint that causes two joint surfaces stick together and thus, joints have different behaviour. Fig. 4 shows shear stress - normal stress plot for the sample with JRC 1 and JRC 2.

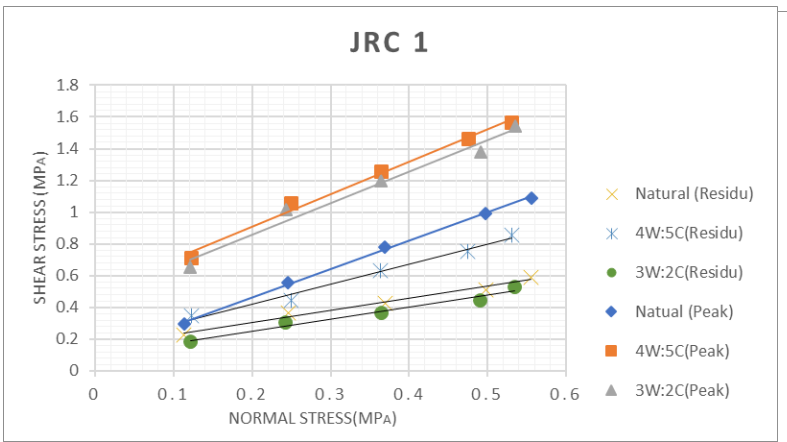

(a)

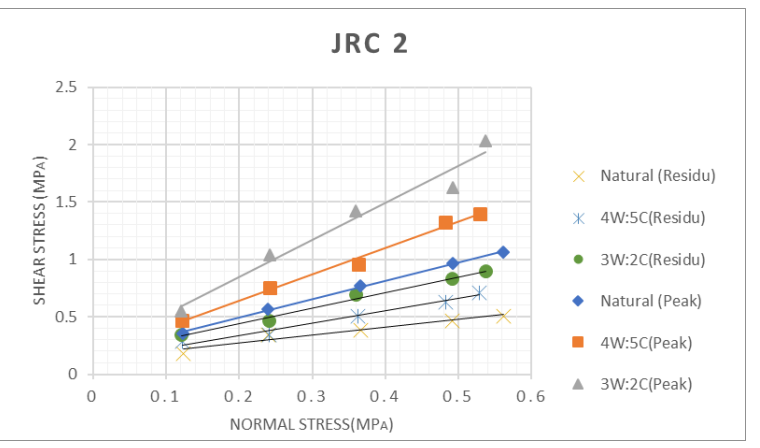

(b)

Fig. 4 Shear stress - Normal Stress plot for (a)JRC 1 and (b) JRC 2

From fig 4, it is revealed that the cement injection changes the shear strength. For the sample with JRC 1, cement injection with water cement ratio of 4:5 increasing rock shear strength better than cement injection with water cement ratio of $3: 2$.
For the sample with JRC 2 cement injection with cement-water ratio of 3:2 increases the shear strength better than cement-water ratio 4:5. For the sample with JRC 3 and JRC 4 are shown in Fig 5.

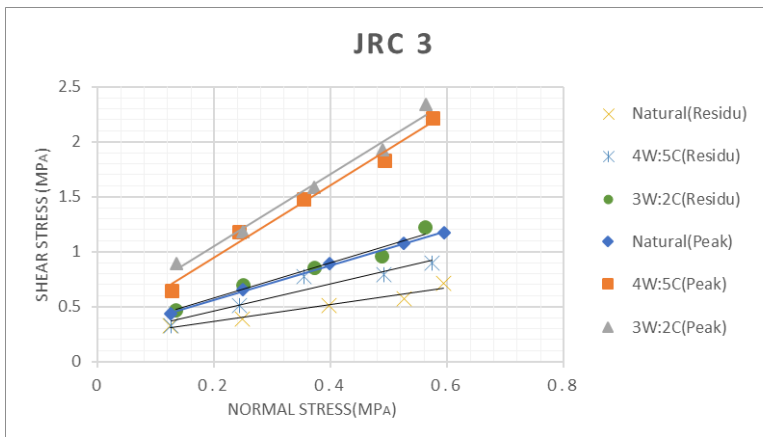

(a)

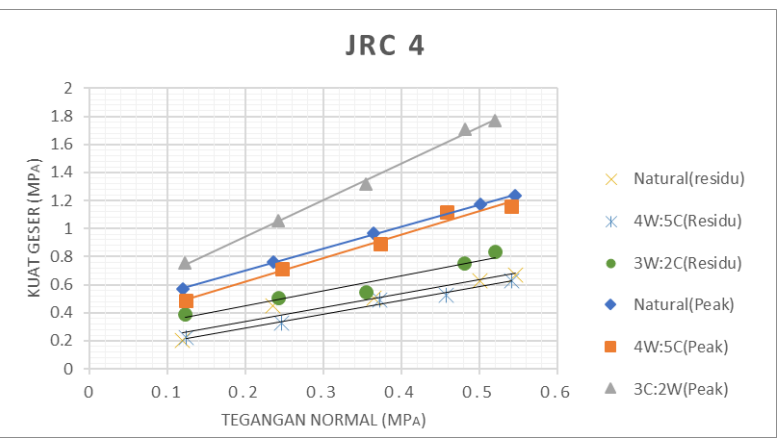

(b)

Fig. 5 Shear stress-Normal stress plot for the sample with (a) JRC 3 (b) JRC 4 
From Fig 5 (a) effect of cement injection in rock shear strength, cement injection with water cement ratio of $3: 2$ increases the shear strength better than cement injection with water to cement ratio of $3: 2$. For JRC 4 something unique was happening, cement ratio of $3: 2$ decreases the rock shear strength. It happens because the capability the grouting suspension to fill all joint

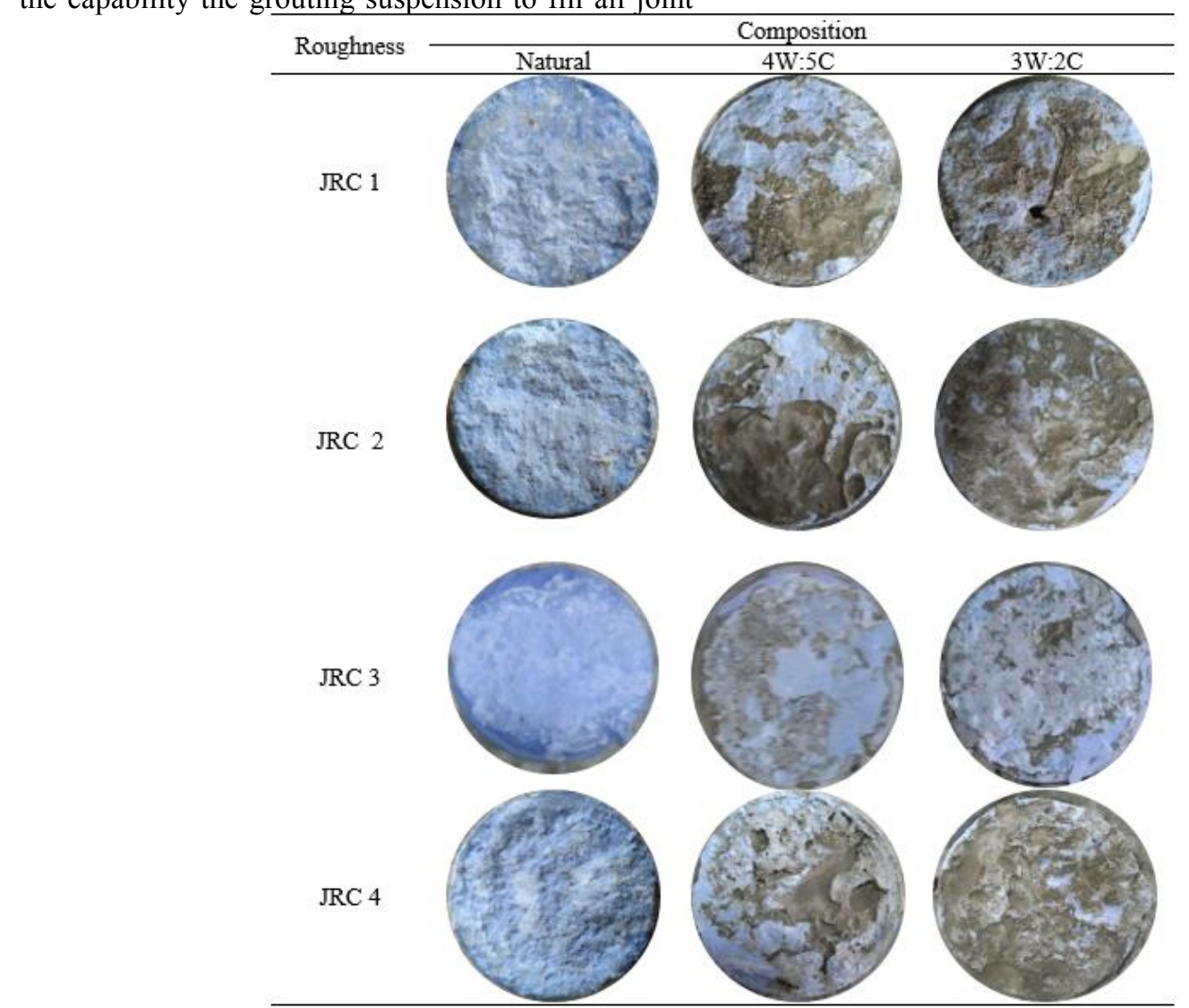

Fig. 6 Result of cement injection process surfaces. In fact, injection material with water to cement ratio of $4: 5$ only fills $57.27 \%$ to $78.32 \%$ joint surface. In another side, cement injection with water to cement ratio of $3: 2$ capable to fill the joint surface higher than $84 \%$. The results of grouting injection in the joint surface are shown in fig 6 .
3.3. Changes in cohesion and internal friction angle As a result of cement injection, the changes of cohesion and internal friction angle depend on JRC value and composition of cement injection. Fig 7 shows the maximum differences of cohesion values between natural joint and the grouted joint, for JRC 1 to JRC 4. It can be concluded that JRC value increase, cohesion will increase too.

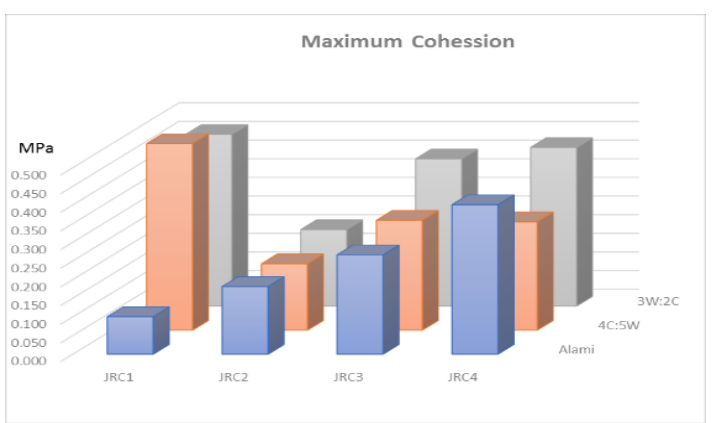

Fig. 7 Maximum cohesion for JRC 1 to JRC 4
Fig 8 shows the change of cohesion on residual condition. It is indicated that JRC value have no effect on residual cohesion value.

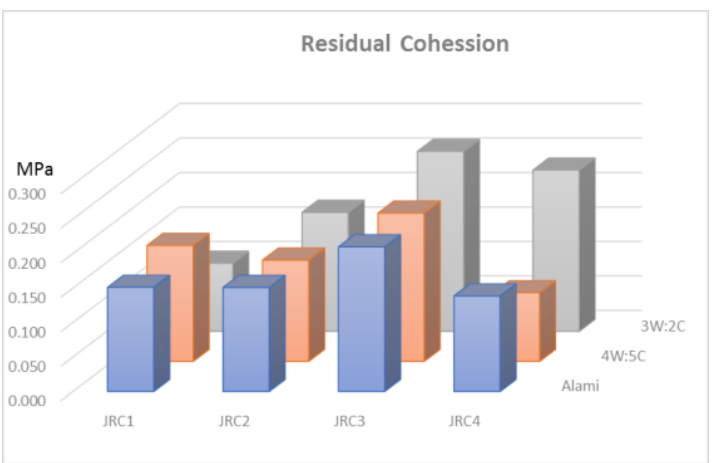

Fig. 8 Changes of residual cohesion value 
Fig 9 shows the change of internal friction angle. It is indicated that increasing JRC value will decrease internal friction angle, and grouting will increase internal friction angle.

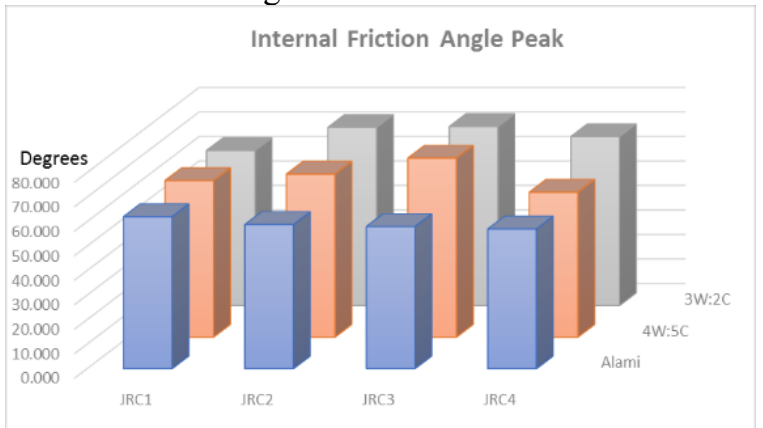

Fig. 9 Changes of maximum Internal fricton angle

Fig 10 shows the change of residual internal friction angle.

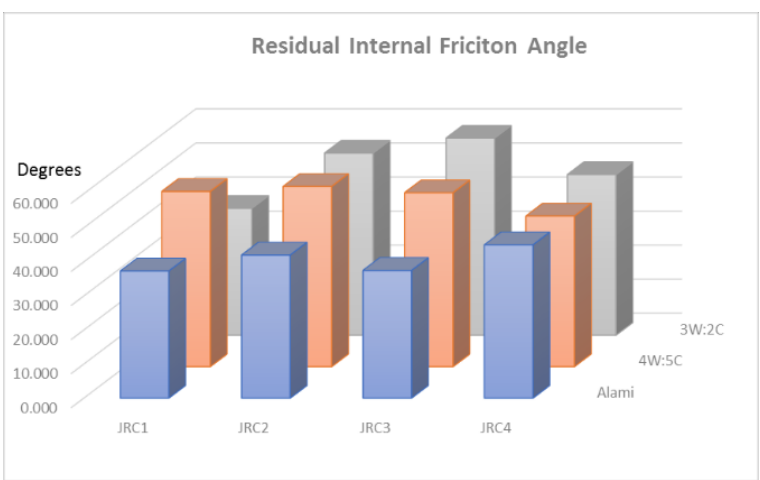

Fig. 10 Changes of Residual internal friction angle

\subsection{Effect of Cement Injection Composition on changes of Cohesion and internal friction angle \\ In this section, cohesion and internal friction angle from the grouted sample and natural sample condition are compared. Table 5 and Table 6 show the changes of cohesion and internal friction angle, respectively.}

Table 5 Changes of cohesion value

\begin{tabular}{lllllllll}
\hline \multicolumn{8}{c}{ Peak (\%) } & \multicolumn{5}{c}{ Residue (\%) } \\
\hline & JRC 1 & JRC 2 & JRC 3 & JRC 4 & JRC 1 & JRC 2 & JRC 3 & JRC 4 \\
\hline NJ & $0 \%$ & $0 \%$ & $0 \%$ & $0 \%$ & $0 \%$ & $0 \%$ & $0 \%$ & $0 \%$ \\
$4 \mathrm{~W}: 5 \mathrm{C}$ & $398 \%$ & $-2 \%$ & $11 \%$ & $-28 \%$ & $11 \%$ & $-3 \%$ & $3 \%$ & $-28 \%$ \\
$3 \mathrm{~W}: 2 \mathrm{C}$ & $359 \%$ & $13 \%$ & $48 \%$ & $6 \%$ & $-35 \%$ & $15 \%$ & $25 \%$ & $69 \%$ \\
\hline
\end{tabular}

Table 6 Changes of internal friction angle value

\begin{tabular}{lllllllll}
\hline \multicolumn{7}{c}{ Internal Friction Angle } \\
\hline \multicolumn{7}{c}{ Peak (\%) } \\
\hline JRC 1 & JRC 2 & JRC 3 & JRC 4 & JRC 1 & JRC 2 & JRC 3 & JRC 4 \\
\hline NJ & $0.0 \%$ & $0.0 \%$ & $0.0 \%$ & $0.0 \%$ & $0.0 \%$ & $0.0 \%$ & $0.0 \%$ & $0.0 \%$ \\
$4 \mathrm{~W}: 5 \mathrm{C}$ & $3.0 \%$ & $13.1 \%$ & $26.0 \%$ & $3.7 \%$ & $37.9 \%$ & $26.0 \%$ & $36.2 \%$ & $-1.7 \%$ \\
$3 \mathrm{~W}: 2 \mathrm{C}$ & $2.0 \%$ & $23.6 \%$ & $26.0 \%$ & $21.0 \%$ & $-0.2 \%$ & $27.4 \%$ & $54.4 \%$ & $4.8 \%$ \\
\hline
\end{tabular}

From table 5 and table 6 , it is indicated that for sample with JRC 1 , cement injection with water to cement ratio of 5:4 is the most effective, because it increases cohesion value $398 \%$ and internal friction angle $3 \%$ from natural condition. While, for the sample with JRC 2, JRC 3, and JRC 4. The most effective grouting composition is $3 \mathrm{~W}: 2 \mathrm{C}$, because of this composition able to increase cohesion value between $6 \%$ to $48 \%$ and for internal friction angle increase between $21 \%$ to $26 \%$ from the sample with the natural condition.

\section{Concluding Remarks}

The test result shows that, as joint roughness increases, the shear strength also increases both for natural joint and grouted joint.

Grouting material will significantly increases the joint shear strength depend on grouting composition. If grouting material is injected with the wrong composition, it may decrease the shear strength. In this study, for low JRC value, grouting material with cement to water ratio of $4: 5$ works effectively to increase the shear strength. In other hands, the sample with high JRC value, the thin grouting material works more efficiently, it can increase the cohesion value from $6 \%$ to $48 \%$ and internal friction angle from $21 \%$ to $26 \%$.

\section{REFERENCES}

Bandis S., Lumdsen, A.C., Barton, N.R Experimental Studies of Scale Effect on Shear Behaviour of Rock Joint, International Journal Rock Mechanics, Mining Science, and Geomechanics, 18, 1-21.(1981).

Barton, N., Bandis, SRock Joints, Barton and Stephenson, Rotterdam: Balkema. .(1980)

Hoek, E., Torres, C.C., Corkum, B, Hoek-Brown Failure Criteria-2002 Edition, Canada: 
Rocscience.(2012)

Houlsby, A.C, Optimum Water:Cement Ratio for Rock Grouting, CGGE, New Oerlans, 317-331.(1982)

Hudson, J.A., Harrison, J.P., Engineering Rock Mechanics an Introduction to The Principles, Great Britain: Pergamon.(1997)

Li, Y., Zhang, Y., Quantitative Estimation of Joint Roughness Coefficient Using Statistical Parameters, International Journal of Rock Mechanics and Mining Sciences, 77, 27-35.(2015)

Lombardy, G., The Role of Cohesion in Cement Grouting of Rock, XVth, ICOLD, Lausanne, 3, 235262.(1985)

Nonveiller, N., Grouting Theory and Practice, Amsterdam : Elsavier.(1989)

Prasettyo, S.H., Gutierrez, M., Barton, N., Nonliniear Shear Behaviour of Rock Joint using Linierazed Implementation of The Barton-Bandis Model, Journal of Rock Mechanics and Geotechnical Engineering, 9, 671-682.(2017)

Rai, M.A., Wattimena, R.K., Karmadibrata,S., Mekanika Batuan, Bandung: ITB Press (2012)

Salamian, et., all., Effect of Grouting on Shear Behaviour of Rock Joint, International Journal of Rock Mechanics and Mining Sciences, 98, 159166.(2017)

Wyllie, D.C., Mah, C.W., Rock Slope Engineering Civil and Mining, London: Spon Press (2005)

Zheng, B., Qi, S., A New Index to Describe Joint Roughness Coefficient (JRC) Under Cyclic Shear, Engineering Geology, 212, 72-85. (2016) 